\title{
Citation:
}

O'Kelly B.C. 2004. Accurate determination of moisture content of organic soils using the oven drying method. Drying Technology, Vol. 22, No. 7, 1767-1776. http://dx.doi.org/10.1081/DRT-200025642

\section{ACCURATE DETERMINATION OF MOISTURE CONTENT OF ORGANIC SOILS USING THE OVEN DRYING METHOD}

Brendan C. O'Kelly

BE, MEngSc, PhD, CEng, MIEI

Lecturer in Civil Engineering, Department of Civil, Structural \& Environmental Engineering, Museum Building, University of Dublin, Trinity College, Ireland and formerly Scott Wilson Consulting Engineers, UK

Tel. +35316083646

Fax. +35316773072

E-mail: bokelly@tcd.ie

First submission: 04 September 2003.

Online Publication Date: 31 December 2004 


\section{ABSTRACT}

The accuracy of moisture content values determined for organic soil using the oven drying method is dependent on the oven drying temperature. Some charring of the organic fraction occurs at the standard oven drying temperature of $110^{\circ} \pm 5^{\circ} \mathrm{C}$; pore water remains in the soil when temperatures below $100^{\circ} \mathrm{C}$ are used.

A new technique to determine the specific oven drying temperature that yields the correct value of the moisture content for organic soils is presented. Routine moisture content tests should be conducted at the standard oven drying temperature; moisture content values determined on the basis of the recommended oven drying temperature of $60^{\circ} \mathrm{C}$ include a larger error. A moisture content parameter is introduced to facilitate direct comparison of moisture content values calculated on the basis of different oven drying temperatures.

Key words and Phrases: Oven drying; Moisture content determination; Organic soil; Particle charring.

\section{INTRODUCTION}

The moisture (water) content is one of the most commonly determined properties in characterizing the engineering behavior of soil. In geotechnical literature, the moisture content is defined as the mass ratio of the pore water to solids, usually expressed as a percentage. According to the definition, the pore water comprises the capillary and hygroscopic water contained in the voids between the solid particles (Head, 1992). The accurate determination of the moisture content is important since the moisture content strongly influences the mechanical behavior of soil. The preferred test method for the laboratory determination of the moisture content is the oven drying method (ASTM D2216, 1998). The moisture content is determined as the reduction in the mass of the test specimen after oven drying, usually at $110^{\circ} \pm 5^{\circ} \mathrm{C}$, expressed as a percentage of its oven dried mass. The equilibrium oven dried mass is usually recorded after between 12 hours and 24 hours oven drying. The method assumes that the reduction in the sample mass is entirely due to the evaporation of the pore water; complete evaporation occurs for drying temperatures exceeding $100^{\circ} \mathrm{C}$. However, oven drying of organic soil at temperatures of $110^{\circ} \pm 5^{\circ} \mathrm{C}$ also causes a reduction in the mass of the solids due to some charring of the organic fraction. For example, MacFarlane and Allen (1963) reported that charring of peat fibers commenced at drying temperatures between $80^{\circ} \mathrm{C}$ and $85^{\circ} \mathrm{C}$.

Moisture content calculations equate potential reductions in the mass of the solid particles due to charring with evaporation of pore water, which results in the true value of the moisture content being overestimated. Lower oven drying temperatures, traditionally in the temperature range between $60^{\circ} \mathrm{C}$ and $80^{\circ} \mathrm{C}$ (Jarrett 1983), are routinely used to prevent charring of the solid organic fraction. ASTM D2216 (1998) recommends using an oven drying temperature of $60^{\circ} \mathrm{C}$ for peat and other organic soils instead of the standard drying temperature of $110^{\circ} \pm 5^{\circ} \mathrm{C}$. However, small quantities of pore water that would otherwise evaporate at $100^{\circ} \mathrm{C}$ remain in the test specimen when lower drying temperatures are used. The remaining moisture in the soil consists of pore water and, for the organic fraction, 
internal capillary water and intracellular water (Möller, 1983). Moisture content calculations will then underestimate the true value of the soil moisture content. Longer drying periods are also required for the dry mass of the sample to equilibrate at lower oven drying temperatures. The correct value of the moisture content, $\mathrm{w}_{\mathrm{c}}$, is determined for the drying temperature at which the mass of the pore water remaining in the soil equals the dry mass loss due to charring of the organic fraction.

Laboratory drying tests were conducted on organic soil to study the sensitivity of the dry mass of the soil to increasing oven drying temperature. A method is presented to determine the particular oven drying temperature for which the correct mass of the solids is measured. The true value of the moisture content of organic soil is calculated based on the sample dry mass corresponding to this oven temperature. The method involves the determination of the equilibrium dry mass of the test specimen for a range of oven drying temperatures, commencing with an initial temperature of approximately $60^{\circ} \mathrm{C}$. In practice, it is quicker to determine the moisture content of organic soil on the basis of the sample dry mass for a drying temperature of $110^{\circ} \pm 5^{\circ} \mathrm{C}$ and then apply a correction to determine the true moisture content value. A method to determine the drying temperature corrections for organic soil is presented and the theoretical basis justified. Moisture content-oven drying temperature correction charts are developed using the test data.

\section{PROCEDURE}

The equilibrium dry mass of the test specimen, typically about $10 \mathrm{~g}$, is determined at set temperatures over a range of oven drying temperatures. A drying oven capable of maintaining the oven chamber temperature within $\pm 1.5^{\circ} \mathrm{C}$ of the set temperature value is recommended. Drying tests commence at an oven temperature of approximately $60^{\circ} \mathrm{C}$; the lower end of the drying temperature range reported for moisture content determinations on organic soil. The mass of the specimen is recorded to $0.01 \mathrm{~g}$, generally at four hour intervals, to determine when the sample mass has equilibrated for each test temperature. In this manner, the organic fraction of the soil experiences the full effects of potential charring for a specific oven temperature. The test specimen is allowed cool in a desiccator container to ambient temperature before recording the sample mass. The equilibrium dry mass of the specimen is determined in this manner for set drying temperatures which increase in value up to an upper limit of approximately $150^{\circ} \mathrm{C}$. The oven temperature is recorded for each drying stage. Distilled water is added to the sample drying container, partially submerging the specimen, after the equilibrium dry mass of the sample has been recorded for the upper temperature limit. The wet test specimen is allowed to re-hydrate fully over several days. The equilibrium dry mass of the test specimen is determined again for an oven drying temperature of $60^{\circ} \mathrm{C}$.

\section{RESULTS}

Oven drying test data is presented in Figure 1 for ten test specimens of the same organic soil determined using the procedure described above. The data is presented as the percentage reduction in the sample dry mass with increasing oven drying temperature, expressed as a percentage of the initial sample dry mass at $60^{\circ} \mathrm{C}$. Some physical properties of the test soil are listed in Table 1. The wet test specimens required 14 days drying at an oven temperature of 
$60^{\circ} \mathrm{C}$ for the sample mass to equilibrate. At higher oven temperatures, only two to three days drying were necessary. Test specimens dried above $95^{\circ} \mathrm{C}$ produced a strong odor.

Table 1. Some properties of the organic soil tested.

\begin{tabular}{ll}
\hline Property & Value \\
\hline Liquid limit & $315 \%$ \\
\hline Plastic limit & $55 \%$ \\
Particle density & $1.55 \mathrm{Mg} / \mathrm{m}^{3}$ \\
Particle size distribution & $90 \%$ dry mass passing $425 \mu \mathrm{m}$ sieve \\
Loss in dry mass on ignition at $440^{\circ} \mathrm{C}$ & $70 \%$ \\
\hline
\end{tabular}

\section{ANALYSIS}

Figure 1 indicates a trend of decreasing sample dry mass with increasing oven drying temperature. The following data are obtained from closer inspection of Figure 1:

- A 5.9\% reduction in the initial sample dry mass occurred on drying the test specimens at the upper oven temperature of $150^{\circ} \mathrm{C}$.

- $2.4 \%$ sample dry mass was recovered on drying the re-hydrated test specimens for the second time at an oven temperature of $60^{\circ} \mathrm{C}$, (point A, Figure 1).

The recovery in the sample dry mass is due to residual pore water in the test specimens at the lower oven temperature which evaporates at $100^{\circ} \mathrm{C}$. The difference of $3.5 \%$ between the initial and final dry mass of the test specimens (points A and B) for the drying temperature of $60^{\circ} \mathrm{C}$ is due to charring of the organic fraction which occurred at higher oven temperatures.

Empirical drying curves, which indicate the contributions of evaporation and oxidation processes in reducing the sample dry mass, are fitted to the data, (Figure 2). An evaporation curve is fitted to the data over the oven temperature range of $60^{\circ} \mathrm{C}$ to $100^{\circ} \mathrm{C}$, with points $\mathrm{B}$ and $\mathrm{C}$ as known start and end points, respectively, for the curve. A second evaporation curve for the re-hydrated test specimens is fitted over the same temperature range, with points A and $\mathrm{D}$ as known start and end points, respectively. The evaporation curves are identical since the removal of pore water from the soil is a reversible process. A best-fit oxidation line is drawn through the data, and tangential to the lower evaporation curve, for oven temperatures of between $80^{\circ} \mathrm{C}$ and $150^{\circ} \mathrm{C}$, corresponding to points $\mathrm{E}$ and $\mathrm{F}$, respectively. The degree of charring is almost directly related to the drying temperature over this temperature range. The data corresponding to the oven drying temperature of $105^{\circ} \mathrm{C}$ is slightly above the best-fit line since the test specimens were first subjected to the latent heat of vaporization of water at this temperature. The oven drying temperature corresponding to the tangent point $\mathrm{E}$, figure 2 , is the temperature at which charring of the susceptible organic fraction largely begins. This occurred at approximately $80^{\circ} \mathrm{C}$ for the test soil and is supported by the fact that oven drying of the test soil only produced a strong odor at higher oven temperatures. MacFarlane and Allen (1963) reported that charring of peat fibers commenced at a drying temperature of approximately $85^{\circ} \mathrm{C}$. 
The true value of the soil moisture content is calculated on the basis of the sample dry mass recorded for the drying temperature corresponding to point $G$, Figure 2. Point $G$ is the intersection point of the oxidation line and the horizontal line which represents complete evaporation of the pore water from the soil. The dry mass of the test specimen at this oven temperature, approximately $87^{\circ} \mathrm{C}$ for the test soil, equals the total mass of the solids prior to heating since the mass of residual pore water exactly compensates for the mass loss of the organic fraction due to charring. Figure 2 indicates that only a $1.1 \%$ dry mass loss occurred due to charring at the standard oven drying temperature of $110^{\circ} \pm 5^{\circ} \mathrm{C}$, for the test soil. Hence, the error in the moisture content value, calculated on the basis of the sample dry mass corresponding to the standard drying temperature of $110^{\circ} \pm 5^{\circ} \mathrm{C}$, is small. The error is actually larger when moisture content calculations are based on the sample dry mass corresponding to the recommended drying temperature of $60^{\circ} \mathrm{C}$ for organic soil.

The true value of the soil moisture content can be determined from moisture content predictions on the basis of the oven dry mass for the standard drying temperature using Eq. (1), once the correct oven drying temperature has been established for the particular soil. The background to Eq. (1) is presented in Appendix I. The benefit of using this approach is that shorter drying periods are required for the mass of the test specimen to equilibrate at the standard drying temperature.

$$
w_{t^{\circ} \mathrm{C}}=\alpha \mathrm{w}_{110^{\circ} \mathrm{C}}-(1-\alpha) \quad(\text { expressed as decimal })
$$

where $\alpha$ is introduced as the moisture content parameter, defined as the ratio of the equilibrium dry masses corresponding to the standard oven drying temperature of $110^{\circ} \pm 5^{\circ} \mathrm{C}$ and a lower oven drying temperature, $\mathrm{t}^{\circ} \mathrm{C}$, in the range $60^{\circ}$ to $110^{\circ} \mathrm{C}$.

Figure 3 presents the moisture content parameter-drying temperature relationship for the test soil. Direct comparisons of moisture content values reported by several researchers but determined on the basis of different oven drying temperatures can be made using Eq. (1) and a chart similar to Figure 3. For example, for the test soil, the correct value of the moisture content and the moisture content value corresponding to an oven drying temperature of $60^{\circ}$ are given by Eqs. (2) and (3), respectively. Values of the $\alpha$ parameter corresponding to these temperatures are 0.983 and 0.960 , respectively, from Figure 3. The same technique can be applied when determining the moisture content of other organic solids that are susceptible to charring.

$$
\begin{aligned}
& w_{C}=0.983 w_{110^{\circ} \mathrm{C}}-0.017 \\
& w_{60^{\circ} \mathrm{C}}=0.96 w_{110^{\circ} \mathrm{C}}-0.04
\end{aligned}
$$

\section{CONCLUSIONS}

A new technique to determine the specific oven drying temperature that yields the correct value of the moisture content for organic soils using the oven drying method is presented. Some slight charring of the organic fraction of the test soil started at an oven drying 
temperature of $80^{\circ} \mathrm{C}$; the degree of charring was directly related to the increase in oven temperature over the test range of $80^{\circ} \mathrm{C}$ to $150^{\circ} \mathrm{C}$.

The standard oven drying temperature of $110^{\circ} \pm 5^{\circ} \mathrm{C}$ should be used for routine moisture content tests. Moisture content values for the test soil determined on the basis of the recommended lower oven drying temperature of $60^{\circ} \mathrm{C}$ included a larger error. Longer drying times were also required for the mass of the test specimens to equilibrate. The correct value of the moisture content for the test soil was determined for an oven drying temperature of $87^{\circ} \mathrm{C}$. A moisture content parameter was introduced to facilitate direct comparison of moisture content values calculated on the basis of different oven drying temperatures.

\section{NOMENCLATURE}

m Total sample mass

$\mathrm{m}_{\mathrm{D}} \quad$ Equilibrium dry mass

$\mathrm{m}_{\mathrm{w}} \quad$ Mass of pore water

w Moisture content, usually as a percentage

$\mathrm{w}_{\mathrm{c}} \quad$ Correct moisture content value

$\alpha \quad$ Moisture content parameter

subscripts

$\mathrm{t}^{\circ} \mathrm{C} \quad$ Oven drying temperature in the range $60^{\circ}$ to $110^{\circ} \mathrm{C}$

$110^{\circ} \mathrm{C}$ Oven drying temperature of $110^{\circ} \pm 5^{\circ} \mathrm{C}$

\section{ACKNOWLEDGEMENTS}

The research was conducted by the author for the MEngSc degree at the Department of Civil Engineering, University College Dublin. The support of Dr Tom Widdis is gratefully acknowledged.

\section{REFERENCES}

ASTM D2216, 1998, Standard Test Method for Laboratory Determination of Water (Moisture) Content of Soil and Rock by Mass. American Society for Testing and Materials, Philadelphia, 5 pp.

Head, K.H., 1992, Manual of Soil Laboratory Testing, Vol. 1, Pentech Press, London, 388 pp.

Jarrett, P.M., 1983, Testing of Peats and Organic Soils, ASTM STP 820, American Society for Testing and Materials, Philadelphia, $241 \mathrm{pp}$.

MacFarlane, I.C. and Allen, C.M., 1963, An Examination of Some Index Test Procedures for Peat, Proc. Ninth Muskeg Research Conference, National Research Council of Canada.

Möller, U.K., 1983, Water Binding, pp. 182-195 in J.B. Carberry and A.J Englande (Eds) Sludge characteristics and behavior. Martinus Nijhoff Publishers, Netherlands. 


\section{APPENDIX I}

The total mass of the soil sample, $\mathrm{m}$, is given by:

$$
m=m_{D}+m_{w}
$$

where $m_{D}$ and $m_{w}$ are the equilibrium dry mass and the mass of the pore water, respectively.

The moisture content is defined in geotechnical literature as,

$$
w=\frac{m_{w}}{m_{D}}
$$

Substituting $\left(m-m_{D}\right)$ for $m_{w}$, from Eq. (4):

$$
w=\frac{m}{m_{D}}-1
$$

Moisture content values, $w_{110^{\circ} \mathrm{C}}$ and $w_{t^{\circ} \mathrm{C}}$, determined on the basis of the standard oven drying temperature of $110^{\circ} \pm 5^{\circ} \mathrm{C}$ and a lower drying temperature, $\mathrm{t}^{\circ} \mathrm{C}$, in the range $60^{\circ}$ to $110^{\circ} \mathrm{C}$, respectively, are given as:

$$
\begin{gathered}
w_{110^{\circ} C}=\frac{m}{m_{D, 110^{\circ} C}}-1 \\
w_{t^{\circ} C}=\frac{m}{m_{D, t^{o} C}}-1
\end{gathered}
$$

where $m_{D, 110^{\circ} \mathrm{C}}$ and $m_{D, t^{\circ} \mathrm{C}}$ are the equilibrium dry masses corresponding to oven drying temperatures of $110^{\circ} \pm 5^{\circ} \mathrm{C}$ and $\mathrm{t}^{\circ} \mathrm{C}$, respectively.

Moisture content calculations equate reductions in the mass of the soil particles due to charring with evaporation of pore water; hence from the calculations point of view there is a perceived conservation of the total sample mass. Rearranging Eqs. (6.1) and (6.2):

$$
\begin{aligned}
m & =w_{110^{o} C} \cdot m_{D, 110^{o} C}+m_{D, 110^{o} C} \\
& =w_{t^{o} C} \cdot m_{D, t^{o} C}+m_{D, t^{o} C}
\end{aligned}
$$


Hence, the moisture content value, $w_{t^{\circ} \mathrm{C}}$ corresponding to an oven drying temperature in the range $60^{\circ}$ to $110^{\circ} \mathrm{C}$ is given as:

$$
w_{t^{o} C}=\alpha w_{110^{\circ} C}-(1-\alpha)
$$

where the moisture content parameter, $\alpha=\frac{m_{D, 110^{\circ} \mathrm{C}}}{m_{D, t^{\circ} \mathrm{C}}}$ 
Figure 1. Reduction in the dry mass of the test soil with increasing oven drying temperature.

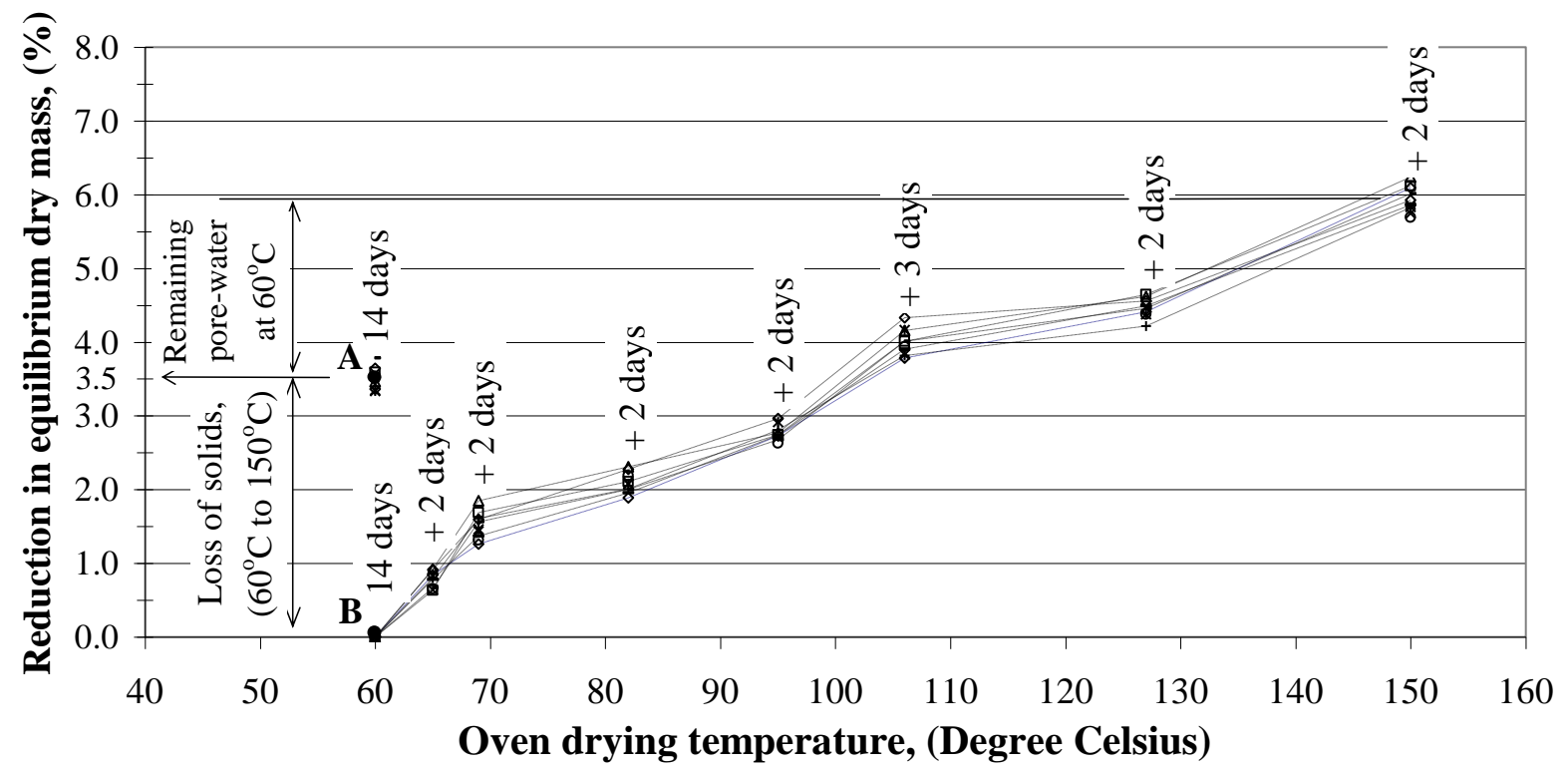

Figure 2. Construction of empirical drying curves.

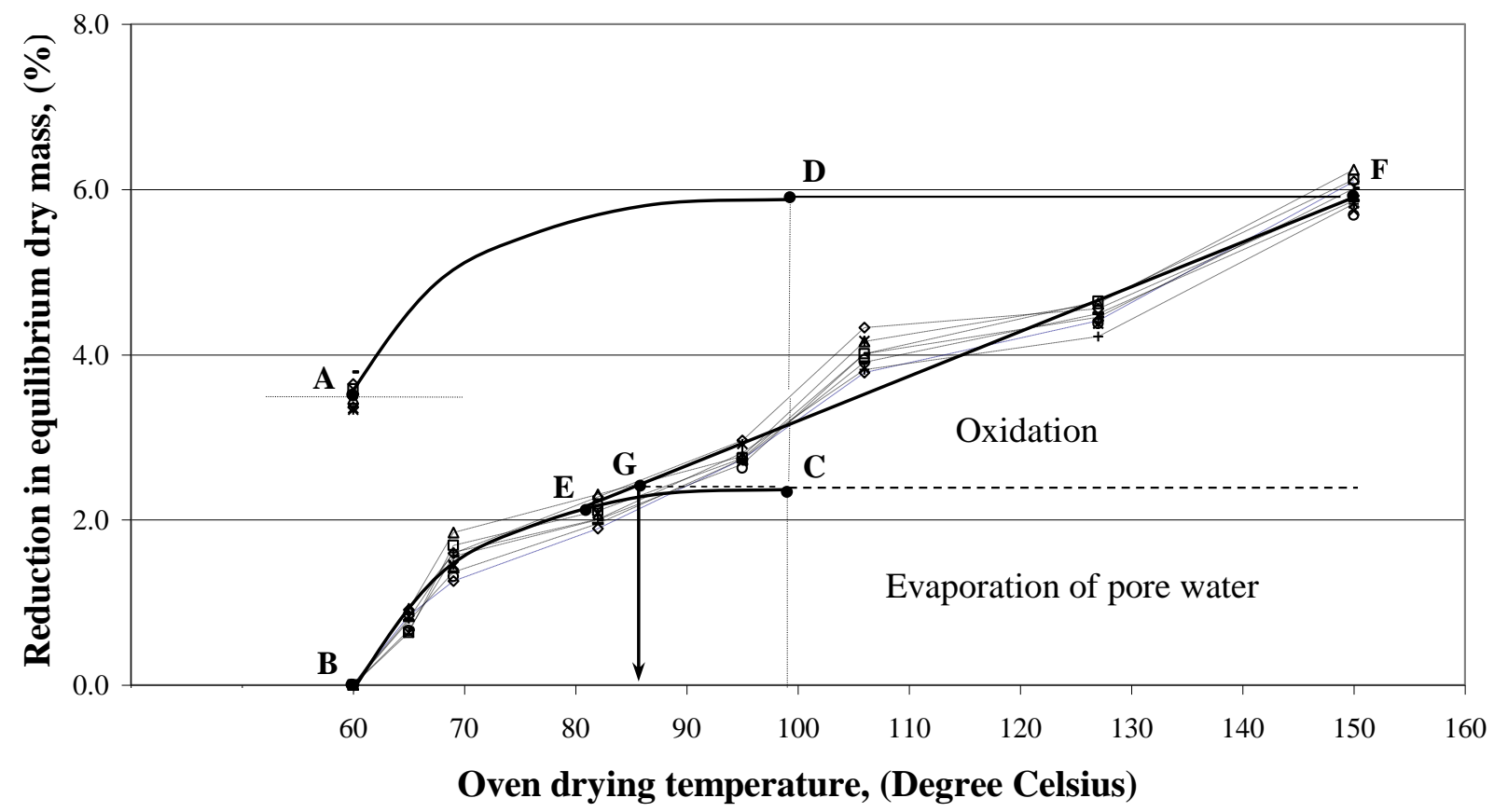


Figure 3. Moisture content parameter-oven drying temperature plot for organic soil.

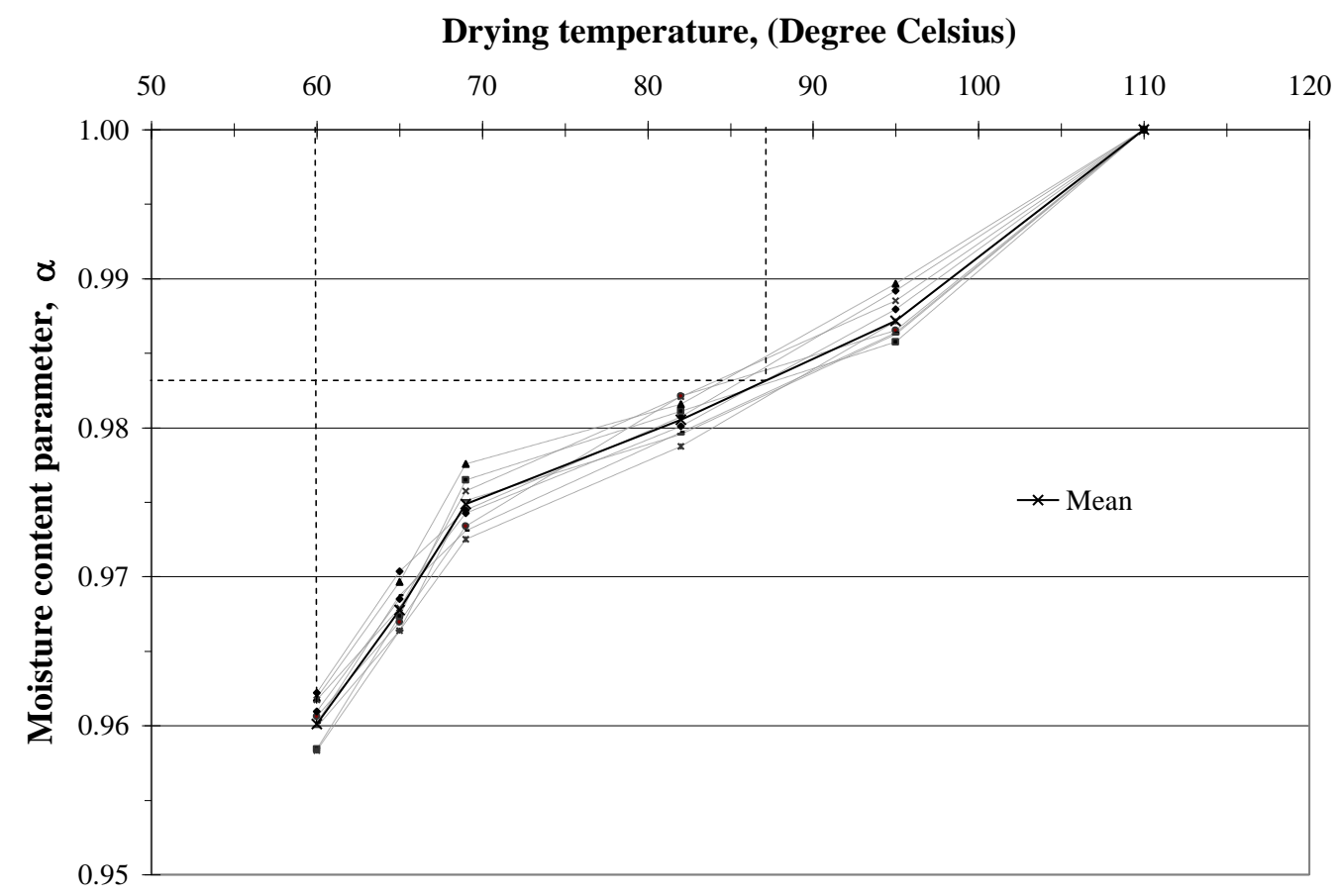

